\title{
A Novel Nature-Inspired Maximum Power Point Tracking (MPPT) Controller Based on SSA-GWO Algorithm for Partially Shaded Photovoltaic Systems
}

\author{
Yihao Wan ${ }^{1, \dagger}$, Mingxuan Mao ${ }^{1,2, *, \dagger}$, Lin Zhou ${ }^{1}$, Qianjin Zhang ${ }^{1}$, Xinze $\mathrm{Xi}^{1,3}$ and Chen Zheng ${ }^{4}$ (I) \\ 1 State Key Laboratory of Power Transmission Equipment \& System Security and New Technology, \\ Chongqing University, Chongqing 400044, China; wanyihao@cqu.edu.cn (Y.W.); zhoulin@cqu.edu.cn (L.Z.); \\ qianjin_zhang@foxmail.com (Q.Z.); cs_xxz@163.com (X.X.) \\ 2 Postdoctoral Station of Electrical Engineering, Chongqing University, Chongqing 400044, China \\ 3 Electric Power Research Institute of Yunnan Power Grid Co., Ltd., Kunming 650217, China \\ 4 State Grid Henan Electric Power Research Institute, Zhengzhou 450052, China; zhengchen725@163.com \\ * Correspondence: mingxuan_mao@cqu.edu.cn \\ $\dagger$ These authors are co-first author.
}

Received: 30 April 2019; Accepted: 13 June 2019; Published: 15 June 2019

check for updates

\begin{abstract}
To overcome the real-time problem of maximum power point tracking (MPPT) for partially shaded photovoltaic (PV) systems, a novel nature-inspired MPPT controller with fast convergence and high accuracy is proposed in this paper. The proposed MPPT controller is achieved by combining salp swarm algorithm (SSA) with grey wolf optimizer (GWO) (namely, SSA-GWO). The leader structure of the GWO algorithm is introduced into the basic SSA algorithm to enhance the global search capability. Numerical simulation on 13 benchmark functions was done to evaluate the proposed SSA-GWO algorithm. Finally, the MPPT performance on PV system with the proposed SSA-GWO algorithm under static and dynamic partial shading conditions was investigated and compared with conventional MPPT algorithms. The quantitative and simulation results validated the effectiveness and superiority of the proposed method.
\end{abstract}

Keywords: Maximum Power Point Tracking (MPPT); Salp Swarm Algorithm (SSA); Grey Wolf optimizer (GWO); Partially Shaded Photovoltaic (PV) System

\section{Introduction}

Over the past decades, the development of renewable energy, especially solar energy, has gained much attention worldwide due to its sustainability, maintenance-free and noise-free characteristics, etc. However, the operation of photovoltaic (PV) systems is highly dependent on external factors, such as solar irradiance and temperature, which has huge implications for the output of PV systems. Therefore, maximum power point tracking (MPPT) controllers are essential to maintain efficient operation of PV modules in a PV system [1]. Recently, a number of references have proposed different MPPT methods based on the power-voltage (P-V) characteristic of the PV modules. In the case of uniform irradiance, the PV array characteristics curve exhibits single peak which can be tracked using conventional MPPT algorithms such as Perturb \& Observe (P\&O) method [2], Incremental Conductance (IC) method [3], and Hill Climbing method [4]. However, when the PV array is exposed to non-uniform radiation, i.e., partial shading conditions (PSCs), the P-V characteristic curve would exhibit multiple peaks and the conventional MPPT methods mentioned above will be trapped in local maximum power point (LMPP), resulting in high power losses of the PV system [5].

To solve the above problem, different algorithms have been proposed. In [6], an improved IC algorithm, which is able to locate the global maximum power point (GMPP) by identifying all the 
LMPPs and GMPP was proposed, but a wide range of inherent information about PV modules are needed. The GMPP tracking (GMPPT) method proposed in [7] is to scan the P-V curve by increasing the output voltage of PV arrays step by step and then employ the P\&O algorithm to locate the GMPP. However, the tracking speed is rather slow, and it requires a high-precision and fast-speed digital processor to implement the method, which will increase the overall cost of the MPPT controller. Other references based on conventional MPPT methods can also be found in [8-10]. In addition, the soft computing methods such as artificial neural network, the fuzzy logic control, bio-inspired algorithms, and chaos theory have been investigated by numerous studies due to their good GMPP tracking performance and simple implementation. Fuzzy logic algorithm [11-13] and artificial neural network [14-16] are applied to MPPT under PSCs, achieving fast tracking speed and small or even zero tracking oscillation at stable state. However, these approaches involve complex computation and the tracking performance is constrained by many factors, such as fuzzy rules, reliable training data in ANN, etc. Besides this, the real-time implementation of the algorithms in MPPT requires the algorithms to respond to the change of external conditions, which is the main disadvantage of offline calculation algorithms like the fuzzy logic algorithm and ANN [17].

Recently, to overcome the aforementioned problems of the conventional MPPT methods, nature-inspired algorithms have come to the fore. The algorithms, including particle swarm optimization (PSO) algorithm [18], artificial fish swarm algorithm (AFSA) [19], artificial bee colony (ABC) algorithm [20] or shuffled frog leaping algorithm (SFLA) [21], grey wolf optimization (GWO) [22,23], etc., exhibit good tracking performance under PSCs. In [24], a novel MPPT method based on PSO is proposed to improve the searching speed and reduce the tracking oscillation by initializing the particles efficiently around the MPP. Another improved PSO algorithm application in MPPT also improves the searching accuracy and reduce the oscillation by selecting proper initial value [25]. Also, the hybrid algorithms, such as combining the conventional MPPT algorithms with bio-inspired algorithms, the hybrid between bio-inspired algorithms, etc., have been proposed to improve the search speed and accuracy, and reduce the oscillation [26-28]. Though these MPPT algorithms have good performance in terms of tracking speed and accuracy, the parameters to be tuned, premature convergence problems, algorithm complexity, etc., have constrained the application to PV systems. The salp swarm algorithm (SSA) [29] has only one control parameter and is simple and easy to implement. Moreover, it can converge to the global optimum due to its adaptive mechanism. Therefore, this paper aimed to propose a novel MPPT algorithm based on the SSA algorithm.

Generally, the MPPT control is achieved by the DC-DC (direct current to direct current) converter, which is the interface between the PV system and the load. Practically, independent control of two series-connected or parallel-connected PV modules with an optimizer can improve the output efficiency of the PV system. Also, the PV module manufacturers focus on the inherent maximum power output capability of cell-strings in a single PV module. With the control of built-in intelligent optimizers, a single PV module is capable of outputting maximum power under partial shading conditions. As for the inverter manufacturer, the dual MPPT inverters structure is employed to make sure that two PV arrays are connected to single inverter. The two PV arrays work independently. When one of the arrays is partially shaded, the other PV array can operate at maximum power without being influenced, which enables the system to have greater energy harvest.

In this paper, a novel nature-inspired SSA-GWO MPPT method is proposed to track the GMPP quickly and accurately under static and dynamic partial shading conditions. In the proposed algorithm, the basic SSA algorithm is optimized by the GWO algorithm to improve the leader structure. Particularly, different from the single leader in SSA algorithm [29], half the salps are selected into a leader group, where the special hierarchy of GWO algorithm is introduced to help the population search globally and rapidly converge to the global optimal region. Moreover, the proposed algorithm still maintains the adaptive mechanism of the basic SSA algorithm, which is able to avoid stagnating in local best solutions. The numerical simulation was tested on 13 benchmark functions to evaluate the performance of the proposed SSA-GWO algorithm. Finally, the PV system with the proposed SSA-GWO MPPT method 
was simulated under static and dynamic partial shading conditions and compared with conventional P\&O, PSO, and basic SSA MPPT methods to validate the effectiveness of this novel MPPT method.

The remainder of the paper is organized as follows. The formulas involving SSA-GWO algorithm and the application in MPPT controller are elaborated on in Section 2. The quantitative analysis and results of the SSA-GWO algorithm and other algorithms are presented in Section 3. The simulations in Section 4 give a comprehensive comparison for the performance of SSA-GWO MPPT algorithm and conventional MPPT algorithms under different PSCs. Finally, the conclusions are given in Section 5.

\section{Proposed MPPT Controller}

\subsection{Description of $S S A$}

SSA is a bio-inspired algorithm proposed by Mirjalili et al. [29]. The salp chain is divided into a single leader and followers. The leader salp is at the front of the chain while the remaining salps in the chain are considered as followers. The position of salps is defined within an n-dimensional search space where $n$ represents the number of variables of given problems. Hence, the position information of salps can be represented by a two-dimensional matrix. The position of the leader salp is updated as follows [29]:

$$
x_{j}^{1}= \begin{cases}F_{j}+c_{1}\left(\left(u b_{j}-l b_{j}\right) c_{2}+l b_{j}\right), & c_{3} \geq 0.5 \\ F_{j}-c_{1}\left(\left(u b_{j}-l b_{j}\right) c_{2}+l b_{j}\right), & c_{3}<0.5\end{cases}
$$

where $x^{1}{ }_{j}$ and $F_{j}$ are the positions of the first salp and food source in $j$ th dimension, respectively; $u b_{j}$ and $l b_{j}$ indicate the upper bound and lower bound of the search space in $j$ th dimension. The equation indicates that the leader only updates the position according to the food source. The parameter $c_{2}$ and $c_{3}$ are random values uniformly generated in the interval of $(0,1)$. Coefficient $c_{1}$ plays an important role in optimization, which is defined as [29]:

$$
c_{1}=2 \cdot e^{-\left(\frac{4 l}{L}\right)^{2}}
$$

where $l$ represents the $l$ th iteration and $L$ is the number of iterations. The initial speed of the salp swarm is zero and the time in optimization is iteration. Therefore, the followers are updated as follows [29]:

$$
x_{j}^{i}=\frac{1}{2}\left(x_{j}^{i}+x_{j}^{i-1}\right)
$$

where $I \geq 2, x_{j}^{i}$ represents the position of $i$ th follower salp in $j$ th dimension. The updating mechanism of salp chains can be modeled by Equations (1)-(3).

The optimization process consists of two stages: exploration and exploitation [29]. The exploration begins with a set of random solutions, which change randomly, rapidly, and abruptly. The main goal of the exploration is to find the promising region in the search space and avoid stagnation in local solutions. After the exploration, the algorithm starts the exploitation stage to improve the accuracy of the potential best solution obtained in the previous stage. The solutions change gradually and locally towards the best solutions. In the movements of the salp chain, the leader salp moves towards the food source while the follower salps follow the leader salp. It is assumed that the current best solution is considered as the food source to be chased by the salp chain, in that the solution to the optimization problem is unknown.

\subsection{Modifying SSA with GWO Algorithm}

In the original SSA algorithm, the single leader plays a dominant role in the exploration. During exploration, the leader is required to change randomly and abruptly to help the whole population search globally. Considering the interactions between the leader and the followers of the SSA algorithm, it is found that the structure of the leader can improve the performance of the whole population. Therefore, in the proposed hybrid algorithm, half the salps are assigned into a leader group, which improves the 
exploration capability of the salp chain due to random distribution of each salp. Furthermore, to guide the follower salps towards the best solution efficiently, the leader group is reconstructed using the GWO algorithm.

In the leader group, the best solution is selected as the alpha $(\alpha)$, and the second and third best solutions are selected as beta $(\beta)$ and delta $(\delta)$, respectively. The rest of the candidate solutions are assumed to be omega $(\omega)$. The position of the grey wolf is expressed as [30]:

$$
\begin{gathered}
\vec{E}=\left|\vec{C} \cdot \overrightarrow{D_{p}}(t)-\vec{D}(t)\right| \\
\vec{D}(t+1)=\overrightarrow{D_{p}}(t)-\vec{A} \cdot \vec{E}
\end{gathered}
$$

where $t$ is the current iteration, $\mathbf{A}$ and $\mathbf{C}$ are coefficient vectors, $D_{p}$ represents the position of the prey, and $\boldsymbol{D}$ is the position of a grey wolf. The vectors $\mathbf{A}$ and $\mathbf{C}$ can be calculated as follows [30]:

$$
\begin{gathered}
\vec{A}=2 \vec{a} \cdot \overrightarrow{r_{1}}-\vec{a} \\
\vec{C}=2 \cdot \overrightarrow{r_{2}}
\end{gathered}
$$

where $a$ decrease linearly from 2 to $0, \boldsymbol{r}_{1}$ and $\boldsymbol{r}_{2}$ are random vectors between 0 and 1 .

The hunting is guided by the leader group, where the alpha, beta, and delta have a better knowledge of the promising area of the prey. The locating process is modeled as follows [30]:

$$
\begin{gathered}
\overrightarrow{E_{\alpha}}=\left|\overrightarrow{C_{1}} \cdot \overrightarrow{D_{\alpha}}-\vec{D}\right|, \overrightarrow{E_{\beta}}=\left|\overrightarrow{C_{2}} \cdot \overrightarrow{D_{\beta}}-\vec{D}\right|, \overrightarrow{E_{\delta}}=\left|\overrightarrow{C_{3}} \cdot \overrightarrow{D_{\delta}}-\vec{D}\right| \\
\overrightarrow{D_{1}}=\overrightarrow{D_{\alpha}}-\overrightarrow{A_{1}} \cdot \overrightarrow{E_{\alpha}}, \overrightarrow{D_{2}}=\overrightarrow{D_{\beta}}-\overrightarrow{A_{2}} \cdot \overrightarrow{E_{\beta}}, \overrightarrow{D_{3}}=\overrightarrow{D_{\delta}}-\overrightarrow{A_{3}} \cdot \overrightarrow{E_{\delta}} \\
\vec{D}(t+1)=\frac{\overrightarrow{D_{1}}+\overrightarrow{D_{2}}+\overrightarrow{D_{3}}}{3}
\end{gathered}
$$

The alpha, beta, and delta in the leader group are simply history memories rather than specific individuals, which is different from the single leader in the SSA algorithm. The leader group will locate the promising solution, which will be chased gradually by the followers. Therefore, with the GWO algorithm, this leader group structure can extend the global search capability of the population as well as improve the accuracy of exploration and exploitation. Generally, the hybrid SSA-GWO algorithm is proposed to enhance the global search capability of the SSA algorithm without altering the adaptive mechanism.

\subsection{MPPT Controller Based on SSA-GWO Algorithm}

In this paper, the MPPT controller produces a duty cycle as the output. Therefore, the duty cycle $d$ is considered as the position of salp swarm, and the corresponding output power of PV arrays is the fitness value. To make the proposed SSA-GWO MPPT controller function under various irradiance conditions, the salps should be distributed appropriately and randomly.

The MPPT begins with the initialization of the salp swarm, of which the positions are distributed within the interval $(0,1)$. Then the fitness values, which are the output power of $P V$ arrays corresponding to each duty cycle, are calculated and compared. The initialized salp is arranged in descending order according to the fitness value and half the salps are chosen as leader. The GWO algorithm is utilized to redistribute the leader group in the course of iteration. Meanwhile, the followers follow the leader group and are updated based on the SSA algorithm. The complete flow chart for the proposed MPPT controller based SSA-GWO algorithm is shown in Figure 1 and the steps are as follows: 
- Step 1: Initialization. In a standard initialization, the salps are usually initialized randomly. For the proposed MPPT algorithm, the salps are initialized within the search space $(0,1)$, where the output voltage corresponding to the position of salps covers a wide range.

- Step 2: Fitness evaluation. The duty cycle, i.e., the position of salps, is connected to the Pulse Width Modulation (PWM). After a fixed period, the corresponding output power is obtained as the fitness of each salp.

- Step 3: Determining the leader group and obtain the food source. The fitness values are sorted in descending order and the first half salps with larger fitness are categorized into leader group while the rest are the followers. The best salp with the largest fitness will be selected as the food source $F$.

- Step 4: Updating the coefficient $c_{1}$. The parameter is updated with Equation (2), which decides the exploration and exploitation.

- Step 5: Updating the leader salps and follower salps. Position of the leaders are updated by Equation (1) and the promising GMPP for the followers to pursue are updated by Equations (4) to (10). Meanwhile, the followers are updated by Equation (3). Besides this, the salps will be amended based on the upper and lower bound of the searching space. If the salps' positions reach the bound, the position of the salp will be set to the corresponding bound.

- Step 6: Calculation of fitness and obtaining the food source. Input the duty ratio of each salp to the power converter and save the corresponding fitness value. The fittest salp will be selected as the food source.

- Step 7: Iteration check. The convergence criterion is checked. If the preset iteration is reached, the calculation will be terminated. Otherwise, steps 2 to 5 will be conducted iteratively until the termination criterion is met.

- Step 8: Reinitialization. In a PV system, the optimum output power is dependent on weather conditions. Therefore, a restart scheme is employed to enable the proposed SSA-GWO MPPT controller to respond rapidly to the irradiance change. The proposed SSA-GWO algorithm will restart when the following equation is satisfied

$$
\frac{\left|P_{\text {real }}-P_{m}\right|}{P_{m}}>\Delta P
$$

where $P_{\text {real }}$ is the measured actual power of PV arrays, $P_{m}$ is the current global MPP of the array. When partial shading conditions occur, $P_{\text {real }}$ will be much lower than $P_{m}$ and $\Delta P$ is set to 0.05 to obtain satisfactory performance. 


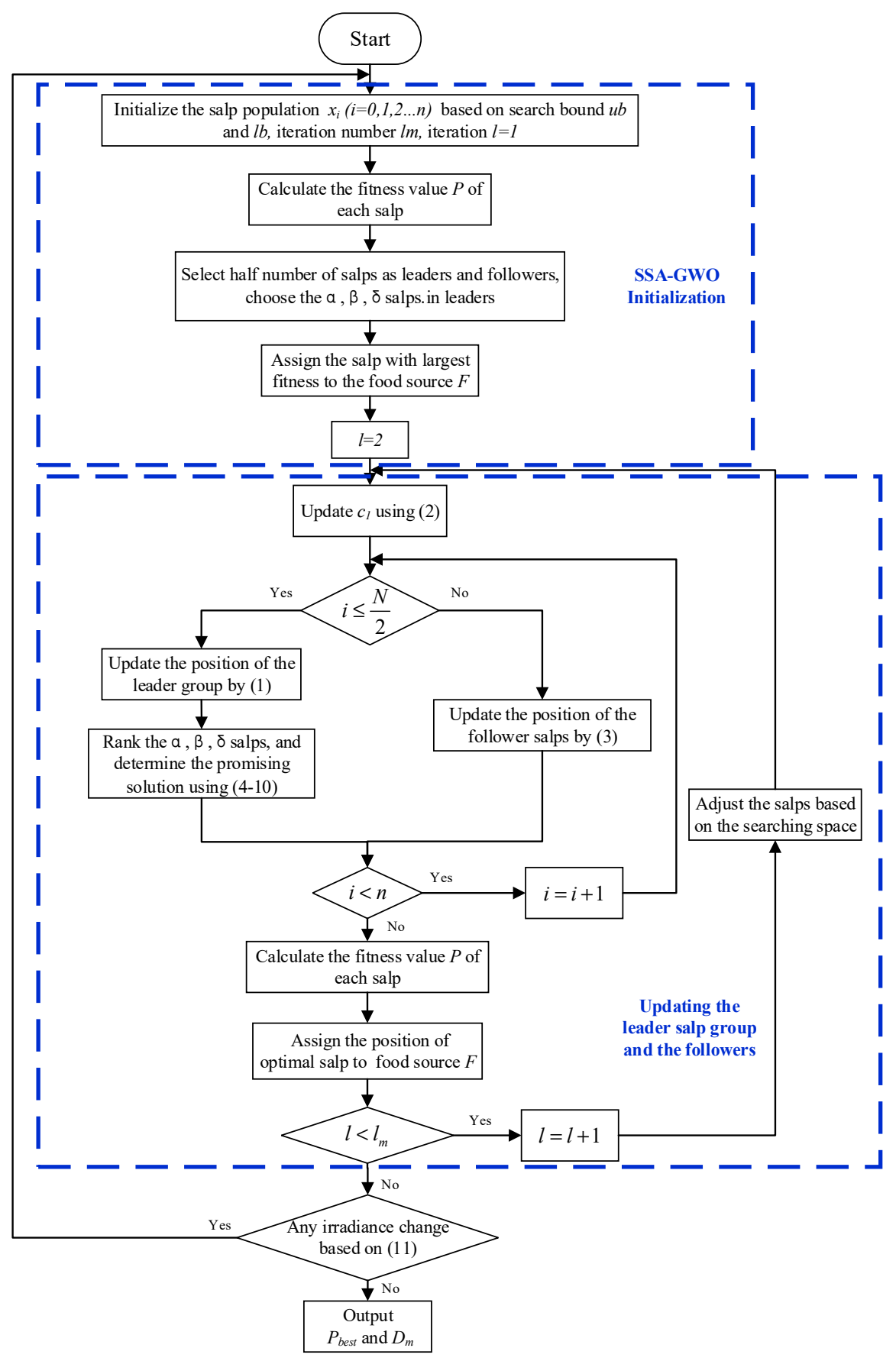

Figure 1. The flowchart of the proposed maximum power point tracking (MPPT) controller based on the Salp Swarm Algorithm-Grey Wolf Optimizer (SSA-GWO) algorithm.

\section{Numerical Simulation Analysis and Discussion}

To evaluate the performance of the proposed SSA-GWO algorithm, a set of mathematical functions were selected $[29,30]$. The benchmark functions consisting of unimodal and multimodal functions are listed in Table 1, where Dim is dimension of the function, search range indicates the boundary of the search space, and $F_{\min }$ is the optimum. Also, the performance of the proposed algorithm was compared with PSO and SSA algorithms. The parameters for different algorithms are given in Table 2. Two indexes were employed to evaluate the performance of the algorithms, mean value and standard deviation (STD) of the best solutions obtained in 300 independent runs. The population size was 50, the dimension was 10 for each benchmark function and the iteration number was 1000. Furthermore, 
the convergence curves for average fitness value in the course of iteration are shown to present the global search capability of different algorithms in avoiding premature convergence. The quantitative results are listed in Table 3.

Table 1. Test benchmark functions.

\begin{tabular}{|c|c|c|c|c|}
\hline Function & Dim & Search Range & Fmin & Type \\
\hline$f_{1}=\sum_{i=1}^{n} x_{i}^{2}$ & 10 & {$[-100,100]$} & 0 & Unimodal \\
\hline$f_{2}=\sum_{i=1}^{i=1}\left|x_{i}\right|+\prod_{i=1}^{n}\left|x_{i}\right|$ & 10 & {$[-10,10]$} & 0 & Unimodal \\
\hline$f_{3}=\sum_{i=1}^{n}\left(\sum_{j-1}^{i} x_{j}\right)^{2}$ & 10 & {$[-100,100]$} & 0 & Unimodal \\
\hline$f_{4}=\max \left\{\left|x_{i}\right|, 1 \leq i \leq n\right\}$ & 10 & {$[-100,100]$} & 0 & Unimodal \\
\hline$f_{5}=\sum_{i=1}^{n-1}\left[100\left(x_{i+1}-x_{i}^{2}\right)^{2}+\left(x_{i}-1\right)^{2}\right]$ & 10 & {$[-30,30]$} & 0 & Unimodal \\
\hline$f_{6}=\sum_{i=1}^{n}\left(\left[x_{i}+0.5\right]\right)^{2}$ & 10 & {$[-100,100]$} & 0 & Unimodal \\
\hline$f_{7}=\sum_{i=1}^{n} i x_{i}^{4}+\operatorname{random}[0,1)$ & 10 & {$[-1.28,1.28]$} & 0 & Unimodal \\
\hline$f_{8}=\sum_{i=1}^{n}-x_{i} \sin \left(\sqrt{\left|x_{i}\right|}\right)$ & 10 & {$[-500,500]$} & $-418.9829 \times 10$ & Multimodal \\
\hline$f_{9}=\sum_{i=1}^{n}\left[x_{i}^{2}-10 \cos \left(2 \pi x_{i}\right)+10\right]$ & 10 & {$[-5.12,5.12]$} & 0 & Multimodal \\
\hline$f_{10}=-20 \exp \left(-0.2 \sqrt{\frac{1}{n} \sum_{i=1}^{n} x_{i}^{2}}\right)-\exp \left(\frac{1}{n} \sum_{i=1}^{n} \cos \left(2 \pi x_{i}\right)\right)+20+e$ & 10 & {$[-32,32]$} & 0 & Multimodal \\
\hline$f_{11}=\frac{1}{4000} \sum_{i=1}^{n} x_{i}^{2}-\prod_{i=1}^{n} \cos \left(\frac{x_{i}}{\sqrt{i}}\right)+1$ & 10 & {$[-600,600]$} & 0 & Multimodal \\
\hline $\begin{array}{l}f_{12}=\frac{\pi}{n}\left\{10 \sin \left(\pi y_{1}\right)+\sum_{i=1}^{n-1}\left(y_{i}-1\right)^{2}\left[1+10 \sin ^{2}\left(\pi y_{i+1}\right)\right]+\left(y_{n}-1\right)^{2}\right\} \\
+\sum_{i=1}^{n} u\left(x_{i}, 10,100,4\right) \\
y_{i}=1+\frac{x_{i}+1}{4} \\
u\left(x_{i}, a, k, m\right)=\left\{\begin{array}{l}k\left(x_{i}-a\right)^{m} x_{i}>a \\
0-a<x_{i}<a \\
k\left(x_{i}-a\right)^{-m} x_{i}<-a\end{array}\right.\end{array}$ & 10 & {$[-50,50]$} & 0 & Multimodal \\
\hline $\begin{array}{l}f_{13}=0.1\left\{\sin ^{2}\left(3 \pi x_{1}\right)+\sum_{i=1}^{n}\left(x_{i}-1\right)^{2}\left[1+\sin ^{2}\left(3 \pi x_{1}+1\right)\right]+\left(x_{n}-1\right)^{2}\left[1+\sin ^{2}\left(2 \pi x_{n}\right)\right]\right\} \\
+\sum_{i=1}^{n} u\left(x_{i}, 5100,4\right)\end{array}$ & 10 & {$[-50,50]$} & 0 & Multimodal \\
\hline
\end{tabular}

Table 2. Parameter settings for different algorithms.

\begin{tabular}{cc}
\hline Algorithm & Parameter Settings \\
\hline PSO & Inertia weight $w=0.9, C 1=C 2=2$ \\
SSA & $C 1:$ Self-adaption \\
SSA-GWO & $a$ and $C 1$ : Self-adaption \\
\hline
\end{tabular}

In Table 3, the proposed SSA-GWO algorithm, PSO, and original SSA algorithm are compared in terms of mean, best, and standard deviation of fitness value. It can be observed that the proposed SSA-GWO algorithm outperforms the other algorithms in most test functions. More precisely, except for the best solution and STD value of Function 5 and the best solution of Function 8, the proposed algorithm has the best performance. 
Table 3. Results comparison for functions $f_{1}-f_{13}$.

\begin{tabular}{|c|c|c|c|c|}
\hline Function & Index & PSO & SSA & SSA-GWO \\
\hline \multirow{3}{*}{$f 1$} & Best & $1.4899 \times 10^{-10}$ & $5.1222 \times 10^{-10}$ & $7.2759 \times 10^{-12}$ \\
\hline & Mean & 0.54751 & $8.2708 \times 10^{-5}$ & $8.5053 \times 10^{-11}$ \\
\hline & STD & 2.6367 & $8.5841 \times 10^{-4}$ & $3.7595 \times 10^{-11}$ \\
\hline \multirow{3}{*}{$f 2$} & Best & 0.025965 & 0.0011806 & $1.101 \times 10^{-6}$ \\
\hline & Mean & 1.8619 & 0.43577 & $2.4873 \times 10^{-6}$ \\
\hline & STD & 1.457 & 0.57199 & $6.1863 \times 10^{-7}$ \\
\hline \multirow{3}{*}{ f3 } & Best & $1.3329 \times 10^{-7}$ & 0.050476 & $3.5286 \times 10^{-10}$ \\
\hline & Mean & 10.3393 & 17.8683 & $2.1272 \times 10^{-9}$ \\
\hline & STD & 25.6427 & 23.4735 & $1.1302 \times 10^{-9}$ \\
\hline \multirow{3}{*}{$f 4$} & Best & 0.38817 & 0.0075142 & $2.2977 \times 10^{-6}$ \\
\hline & Mean & 5.2313 & 1.481 & $4.8977 \times 10^{-6}$ \\
\hline & STD & 3.1815 & 1.6162 & $1.2188 \times 10^{-6}$ \\
\hline \multirow{3}{*}{$f 5$} & Best & 0.00081823 & 0.0035541 & 0.095366 \\
\hline & Mean & 164.4538 & 208.8242 & 128.3479 \\
\hline & STD & 332.6081 & 444.9757 & 371.3509 \\
\hline \multirow{3}{*}{ f6 } & Best & 0.0041224 & 0.00067943 & 0.00021082 \\
\hline & Mean & 0.53906 & 0.01156 & 0.0021277 \\
\hline & STD & 0.29003 & 0.0096091 & 0.0014936 \\
\hline \multirow{3}{*}{ f8 } & Best & $-\operatorname{Inf}$ & -3716.0755 & -3714.5585 \\
\hline & Mean & - Inf & -2763.9914 & -2874.5761 \\
\hline & STD & $\mathrm{NaN}$ & 330.2627 & 318.3991 \\
\hline \multirow{3}{*}{ f9 } & Best & 2.9851 & 2.9849 & 0.99496 \\
\hline & Mean & 19.8398 & 14.4535 & 11.0971 \\
\hline & STD & 8.4259 & 7.1933 & 5.4115 \\
\hline \multirow{3}{*}{ f10 } & Best & 0.12402 & $2.1373 \times 10^{-5}$ & $1.7439 \times 10^{-6}$ \\
\hline & Mean & 5.2821 & 2.3401 & 0.32278 \\
\hline & STD & 2.0648 & 1.1404 & 0.70685 \\
\hline \multirow{3}{*}{$f 11$} & Best & 0.06798 & 0.039666 & $2.2012 \times 10^{-10}$ \\
\hline & Mean & 0.87126 & 0.32775 & 0.10671 \\
\hline & STD & 0.59614 & 0.20514 & 0.082469 \\
\hline \multirow{3}{*}{$f 12$} & Best & 0.0003799 & 0.013168 & $2.8442 \times 10^{-12}$ \\
\hline & Mean & 4.2438 & 2.7214 & 0.037527 \\
\hline & STD & 4.3704 & 2.2349 & 0.16814 \\
\hline \multirow{3}{*}{$f 13$} & Best & 0.0010674 & $2.364 \times 10^{-5}$ & $1.235 \times 10^{-11}$ \\
\hline & Mean & 4.1882 & 0.37209 & 0.0018249 \\
\hline & STD & 5.8115 & 1.4615 & 0.0042647 \\
\hline
\end{tabular}

Figure 2 shows the convergence curves of the three algorithms for six selected benchmark functions, including unimodal and multi-modal functions. As analyzed in Section 2.2, the proposed SSA-GWO algorithm has improved global search capability compared with SSA by restructuring the leader group, while maintaining the adaptive mechanism of SSA. In Figure 2, all the three algorithms converge successfully, while it can be observed that the initial convergence speed of PSO algorithm is fast. Also, the fitness value of SSA-GWO and SSA algorithm is lower than its PSO counterpart. In the middle stage of iteration, both the SSA-GWO and SSA maintained a fast convergence speed while the convergence speed of PSO was reduced to a low level. To be precise, the convergence speed of SSA-GWO algorithm was even faster than SSA algorithm in the middle stage. In the late stage of iteration, the fitness value of SSA-GWO and SSA algorithm was lower than PSO, and the fitness value using SSA-GWO was able to converge to the lowest level.

The results validate the analysis in Section 2.2, wherein by halving the salp chain into leaders and followers, the global search capability of the proposed SSA-GWO algorithm is improved and the introduction of GWO algorithm in leader group enables the SSA-GWO to converge faster in the course of iteration. Therefore, the SSA-GWO algorithm has better performance in terms of convergence speed and accuracy. 


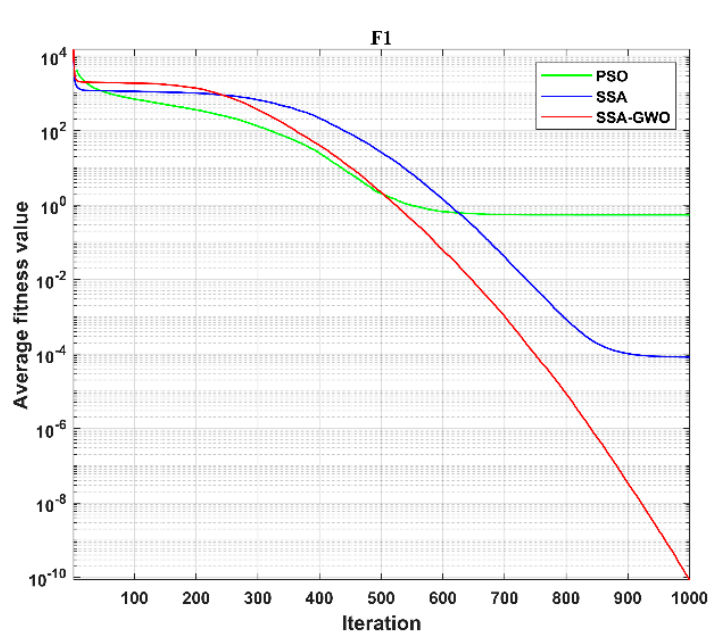

(a)

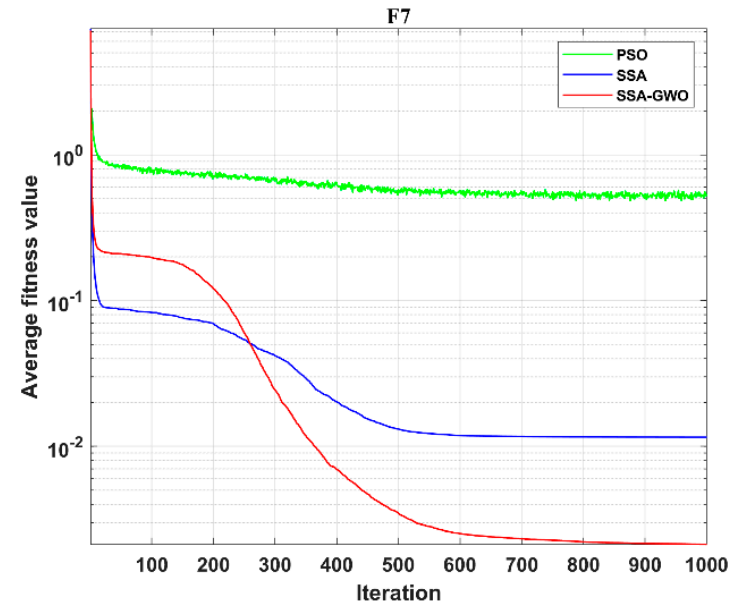

(c)

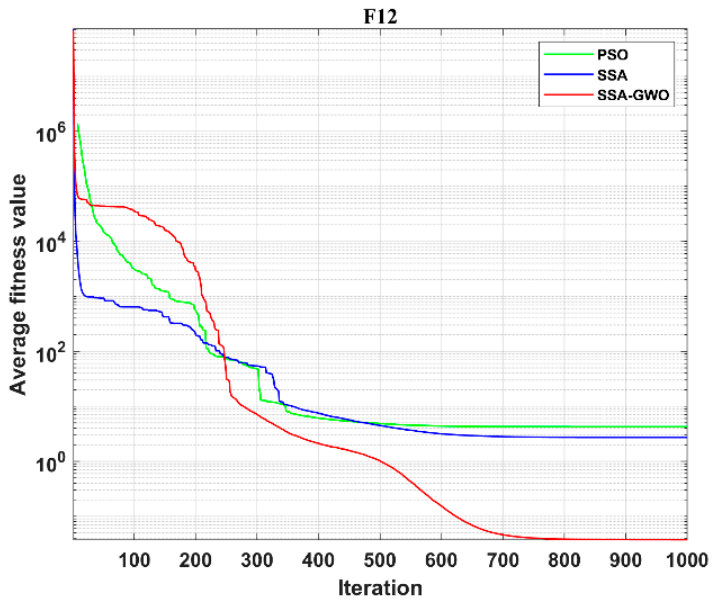

(e)

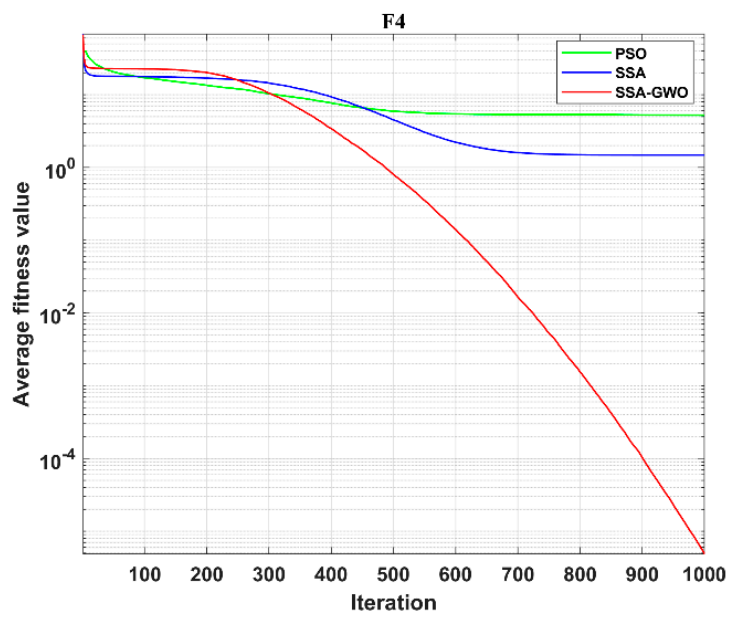

(b)

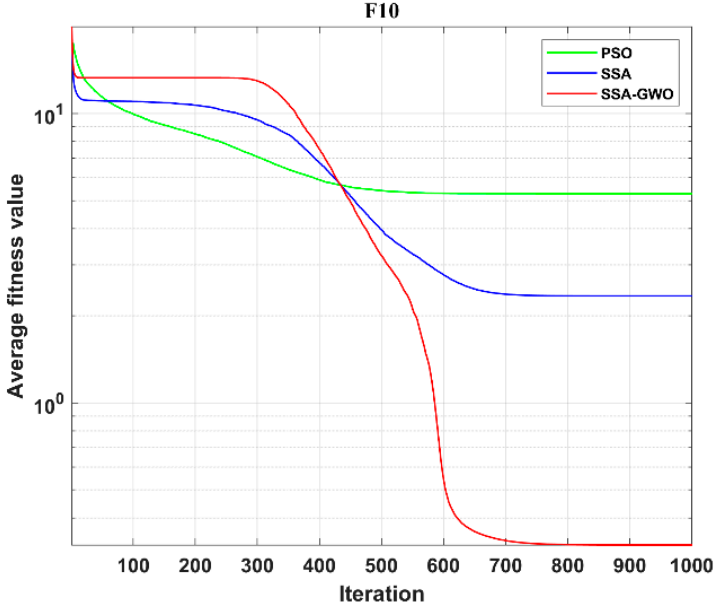

(d)

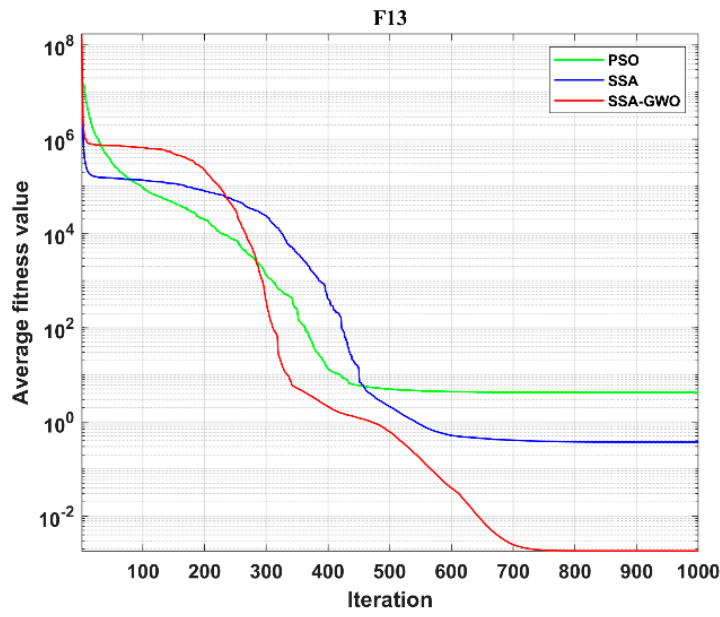

(f)

Figure 2. The optimization curve of test functions: (a) function 1; (b) function 4; (c) function 7; (d) function 10; (e) function 12; (f) function 13.

\section{Simulation of PV System under Static and Dynamic PSCs}

To test the proposed SSA-GWO performance in MPPT, a PV system consisting of series-connected PV arrays with Buck-Boost converter was established as depicted in Figure 3. 


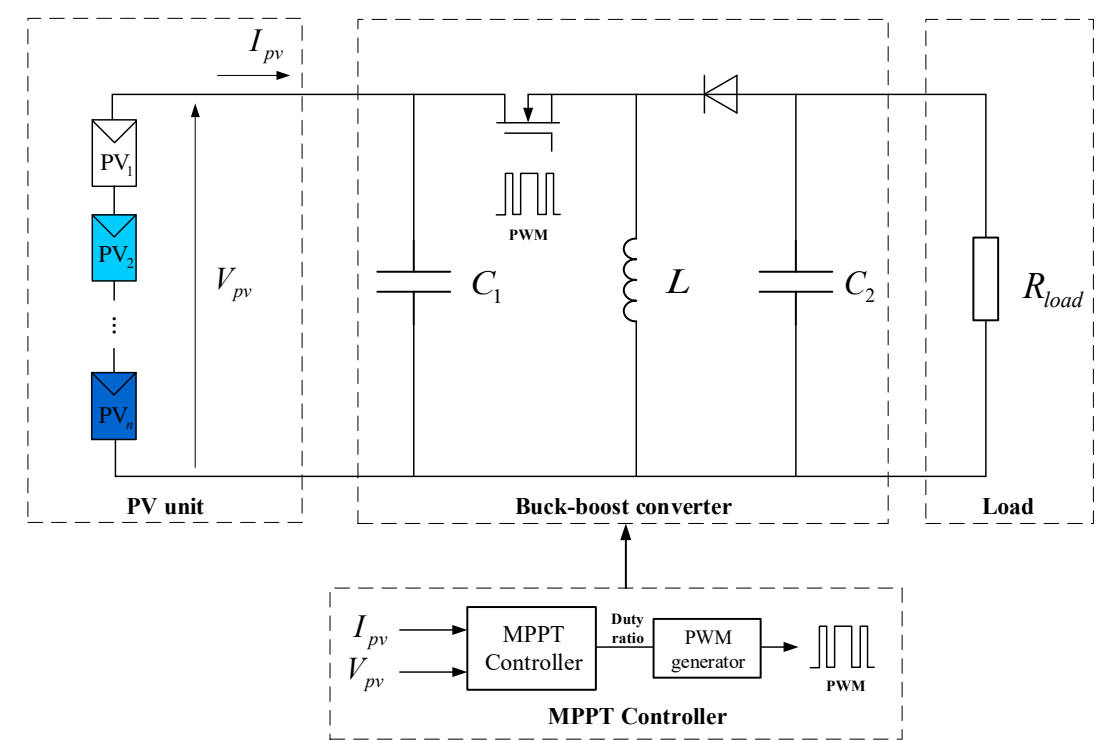

Figure 3. Photovoltaic (PV) power generation system with Buck-Boost converter.

The equivalent circuit of PV cell is shown in Figure 4 , including $N_{p}$ parallel-connected PV modules and $N_{s}$ series-connected PV modules [31]. The I- $V$ characteristics of single PV module can be expressed as [31]:

$$
I_{\text {out }}=N_{P} I_{\text {ph }}-N_{P} I_{s}\left\{\exp \left[\frac{q\left(V_{\text {out }} / N_{S}+I_{\text {out }} R_{S T}\right)}{A K T_{c}}\right]-1\right\}-\frac{N_{P} \frac{V_{\text {out }}}{N_{s}}+I_{\text {out }} R_{s}}{R_{P T}}
$$

where $I_{p h}$ is the photocurrent, $I_{S}$ is the reverse saturation current of diode $D, A$ is diode ideality factor, $q$ is the electron charge $\left(1.609 \times 10^{-19} \mathrm{C}\right), T_{\mathcal{c}}$ is the cell absolute temperature in $\mathrm{K}$ and $\mathrm{K}$ is Boltzmann's constant. The equivalent series and shunt resistance are $R_{S T}=R_{S} \cdot N_{S} / N_{P}$ and $R_{P T}=R_{P} \cdot N_{P} / N_{S}$, respectively.

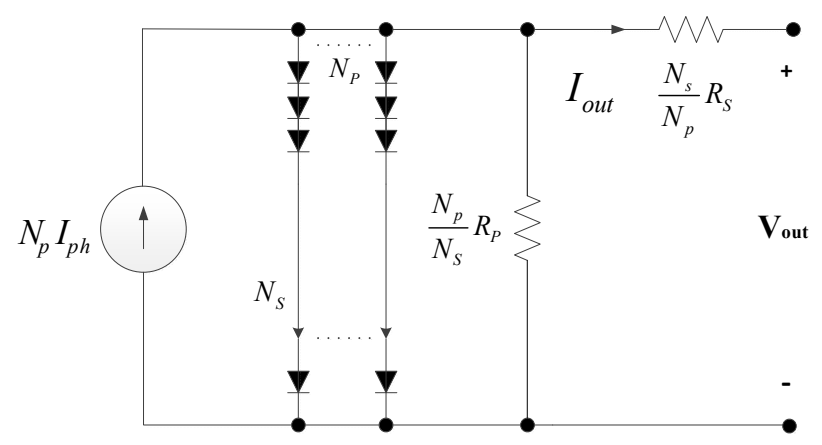

Figure 4. Equivalent circuit model of a PV module.

The parameters of single PV module are listed in Table 4. The circuit parameters are as follows: $\mathrm{L}=0.8 \mathrm{mH}, \mathrm{C}_{1}=220 \mu \mathrm{F}, \mathrm{C}_{2}=220 \mu \mathrm{F}$, and the switching frequency is $20 \mathrm{kHz}$.

Table 4. Parameters of a single PV module.

\begin{tabular}{cc}
\hline Parameter & Value \\
\hline Maximum power $\left(P_{m}\right)$ & $35 \mathrm{~W}$ \\
Open circuit voltage $\left(V_{o c}\right)$ & $21.6 \mathrm{~V}$ \\
Maximum power voltage $\left(V_{m}\right)$ & $17.6 \mathrm{~V}$ \\
Short circuit current $\left(I_{s c}\right)$ & $1.98 \mathrm{~A}$ \\
Maximum power current $\left(I_{m}\right)$ & $2.25 \mathrm{~A}$ \\
\hline
\end{tabular}


To evaluate the performance of the proposed algorithm in MPPT, it has been compared with conventional P\&O and PSO MPPT algorithms. The step size of the P\&O algorithm is $\Delta d=0.05$, and the parameters of PSO algorithm are inertia weight $\omega=0.4$, factors $c_{1}=1.2$ and $c_{2}=1.2$.

\subsection{Complex Static Partial Shading Condition}

Ten series-connected PV modules with irradiance ranging from $100 \mathrm{~W} / \mathrm{m}^{2}$ to $1000 \mathrm{~W} / \mathrm{m}^{2}$ were implemented to verify the MPPT performance of the proposed algorithm. The $P-V$ characteristic curve of the PV system is shown in Figure 5. The maximum output power of the system was $116.9 \mathrm{~W}$.

The simulation results of the PV system using different MPPT algorithms are shown in Figure 6. Generally, the performance of MPPT algorithms can be evaluated by the tracking speed, accuracy, and oscillation. It can also be evaluated by the MPPT tracking efficiency, which is expressed as:

$$
\eta=\frac{P_{\max }}{P_{\text {real }}}
$$

where $P_{\text {real }}$ is the theoretical global maximum output power of the PV system under different irradiance patterns, and $P_{\max }$ is the maximum output power of PV system using various MPPT algorithms.

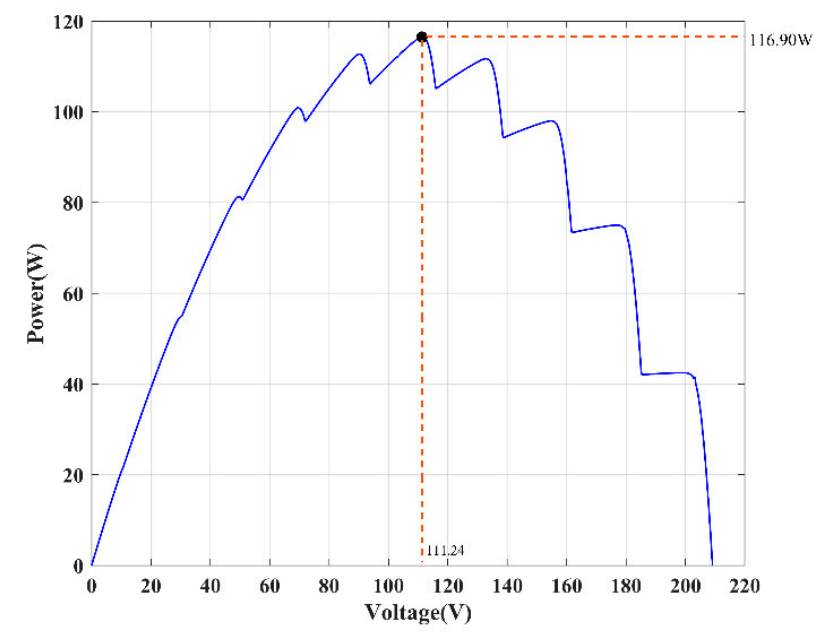

Figure 5. Power-Voltage (P-V) curve of ten series-connected PV arrays.

The output waveform in Figure 6, along with the statistical results in Table 5, gives a comprehensive comparison of different MPPT algorithms. Though it takes only $0.16 \mathrm{~s}$ for the conventional P\&O algorithm to track an MPP, the output power is much lower than the counterpart algorithms. It took $1.09 \mathrm{~s}, 0.92 \mathrm{~s}$, and $0.68 \mathrm{~s}$ for the PSO, SSA, and proposed SSA-GWO algorithms to track the GMPP, where the output powers of PV system were $116.53 \mathrm{~W}, 116.59 \mathrm{~W}$, and $116.69 \mathrm{~W}$, respectively. The tracking efficiency for the four algorithms was $86.25 \%, 99.68 \%, 99.73 \%$, and $99.82 \%$. Therefore, the proposed SSA-GWO algorithm outperforms the other algorithms in terms of tracking speed and efficiency. In addition, it can be observed that the oscillation of the proposed MPPT algorithm is reduced compared with other algorithms. 


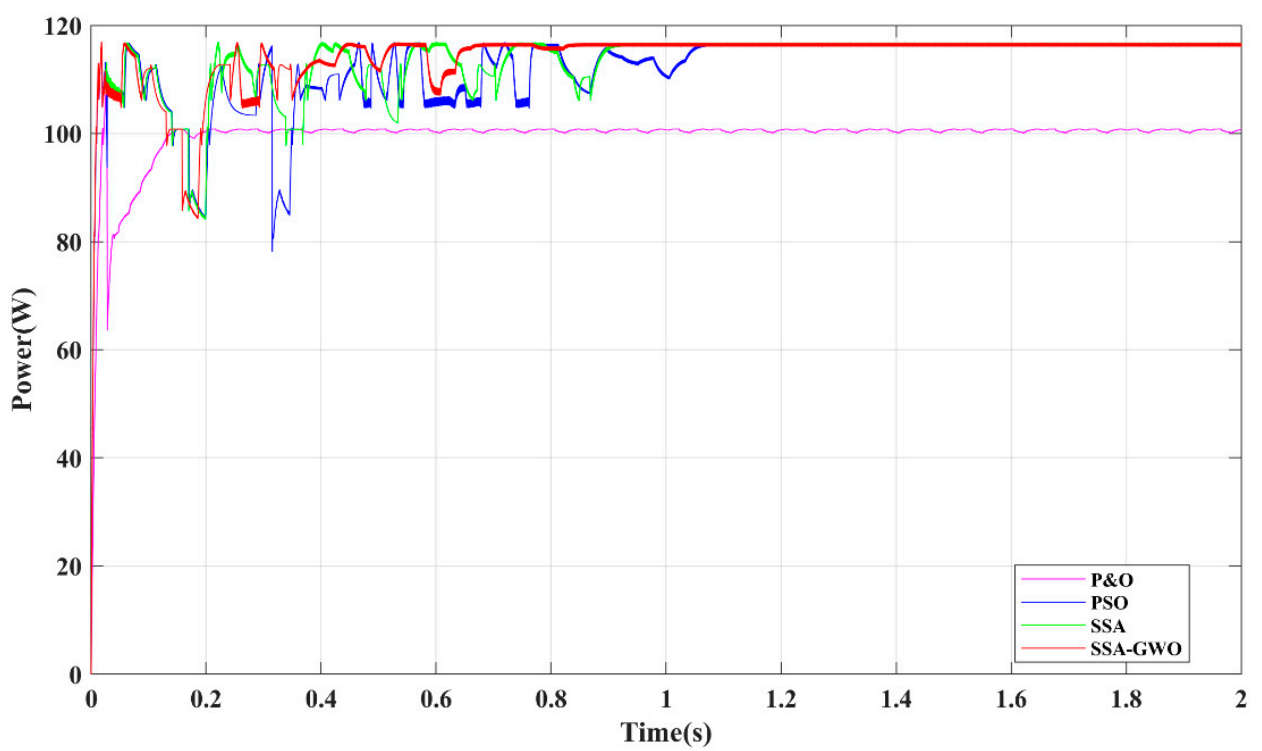

Figure 6. Output waveforms of the PV system using different MPPT algorithms.

Table 5. Performance comparison of different MPPT algorithms.

\begin{tabular}{cccc}
\hline Algorithms & $\boldsymbol{P}_{\max }(\mathbf{W})$ & MPPT Efficiency & Tracking Time (s) \\
\hline P\&O & 100.83 & $86.25 \%$ & 0.16 \\
PSO & 116.53 & $99.68 \%$ & 1.09 \\
SSA & 116.59 & $99.73 \%$ & 0.92 \\
SSA-GWO & 116.69 & $99.82 \%$ & 0.82 \\
\hline
\end{tabular}

\subsection{Dynamic Performance Under Sudden Irradiance Change}

To further evaluate the performance of the proposed SSA-GWO algorithm, it was applied to the system under dynamic irradiance change. A PV system with three series-connected PV arrays using different MPPT algorithms was implemented. The irradiation patterns of the three PV modules are given in Table 6. The corresponding $P-V$ characteristic curves are shown in Figure 7 . The maximum output powers of the PV system were $105 \mathrm{~W}, 69.4 \mathrm{~W}$, and 44.6 W for Pattern I, II, and III respectively.

Table 6. Irradiance patterns.

\begin{tabular}{cccc}
\hline \multirow{2}{*}{ Pattern } & \multicolumn{3}{c}{ Irradiance of $\mathbf{P V}$ modules $\left(\mathbf{W} / \mathbf{m}^{\mathbf{2}}\right)$} \\
\cline { 2 - 4 } & $\mathbf{G}_{\mathbf{1}}$ & $\mathbf{G}_{\mathbf{2}}$ & $\mathbf{G}_{\mathbf{3}}$ \\
\hline 1 & 1000 & 1000 & 1000 \\
2 & 1000 & 600 & 300 \\
3 & 1000 & 800 & 600 \\
\hline
\end{tabular}




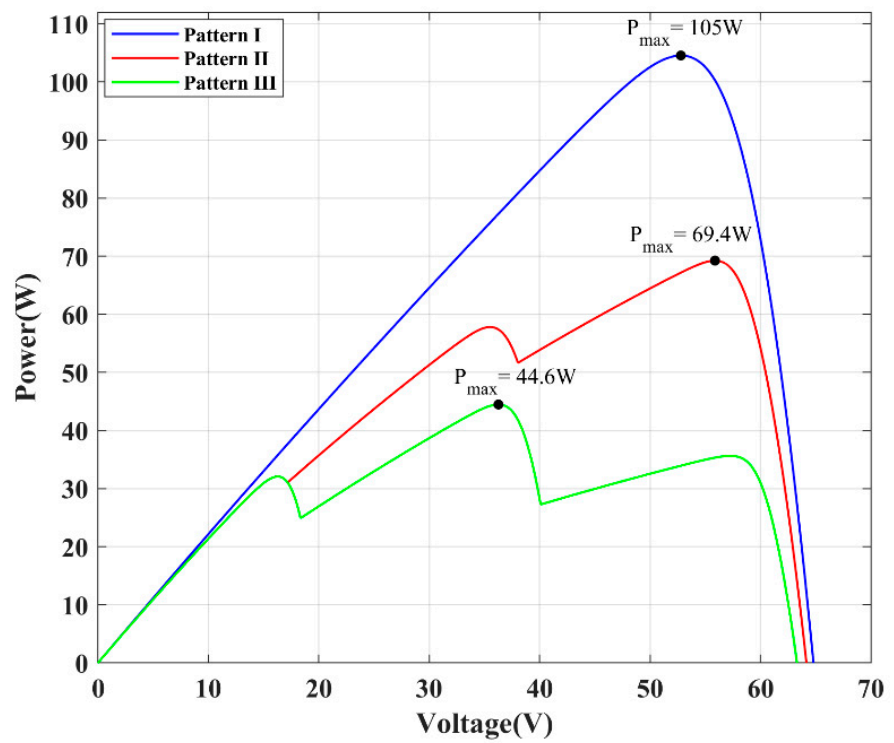

Figure 7. P-V characteristic curves of the PV array under partial shading conditions (PSCs).

Different MPPT methods, including P\&O, PSO, SSA, and the proposed SSA-GWO MPPT algorithm, were applied to the system. The simulation was performed under dynamic irradiance change. To ensure that the MPPT algorithms were able to track the new GMPP under changing irradiance, a re-initialization technique was implemented. The waveforms of output power and duty cycle using different MPPT methods are presented in Figure 8, which are divided into three intervals, representing three different irradiance patterns. The statistical results are given in Table 7.

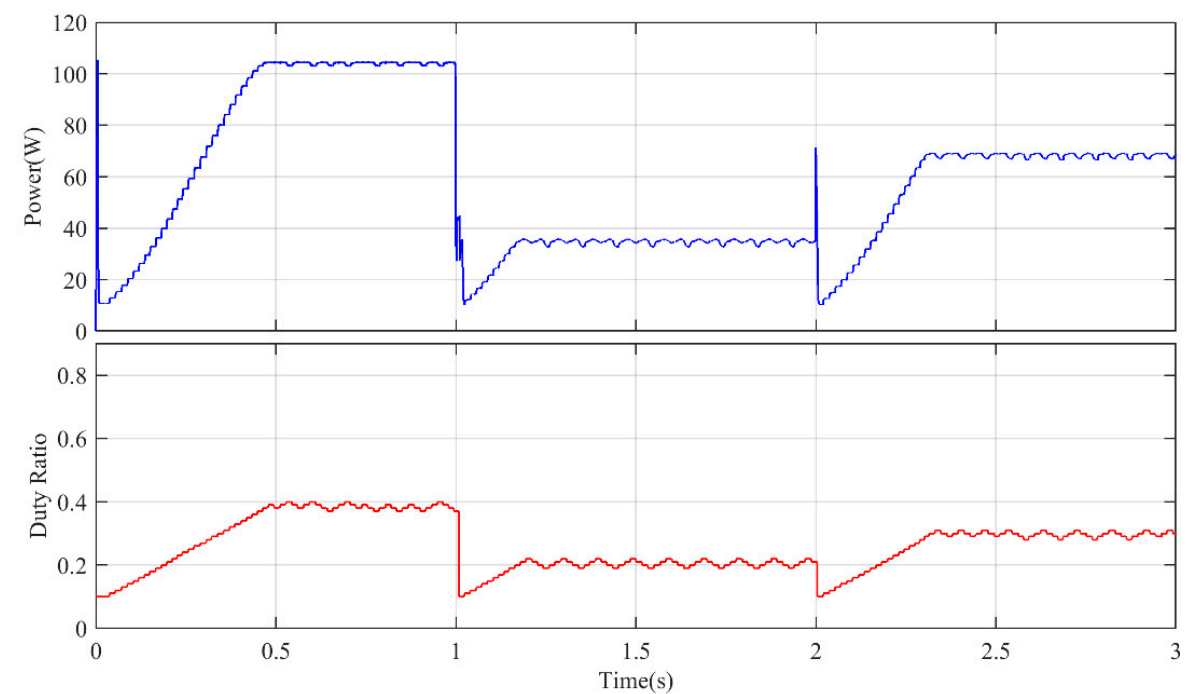

(a)

Figure 8. Cont. 


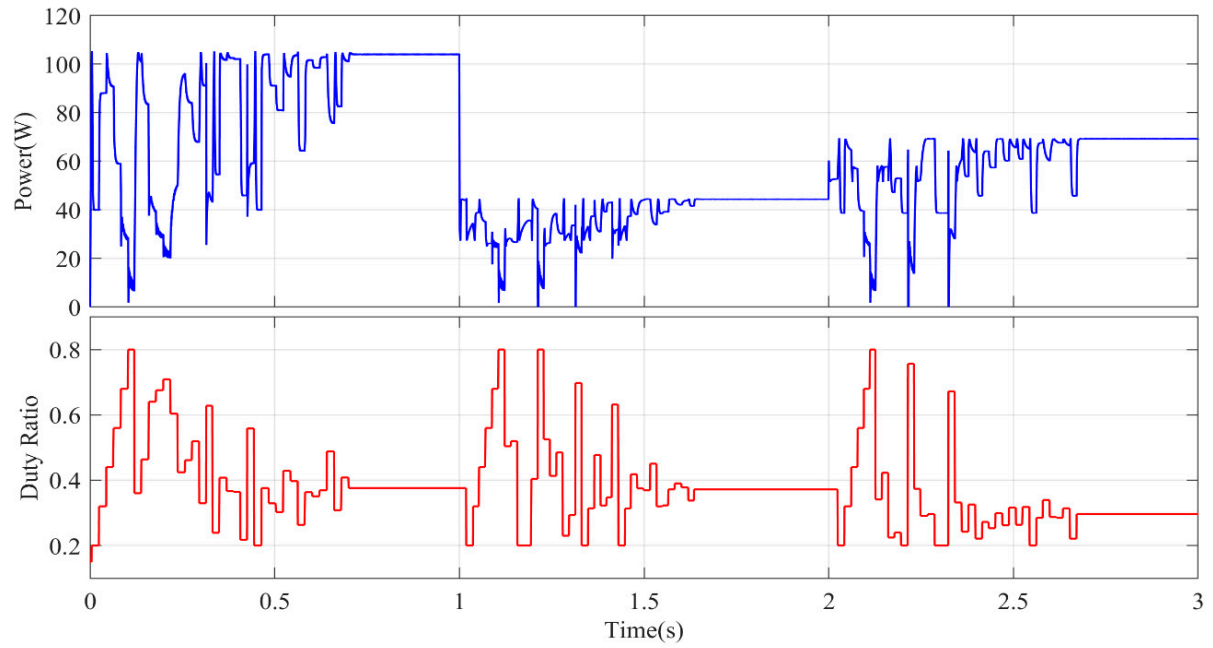

(b)

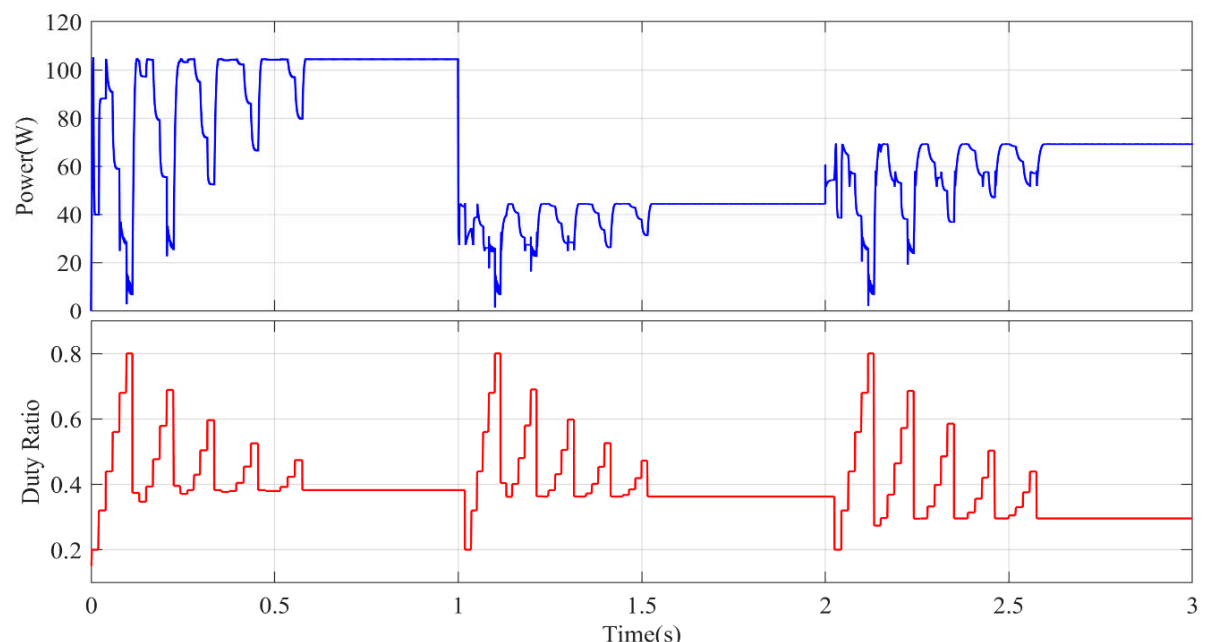

(c)
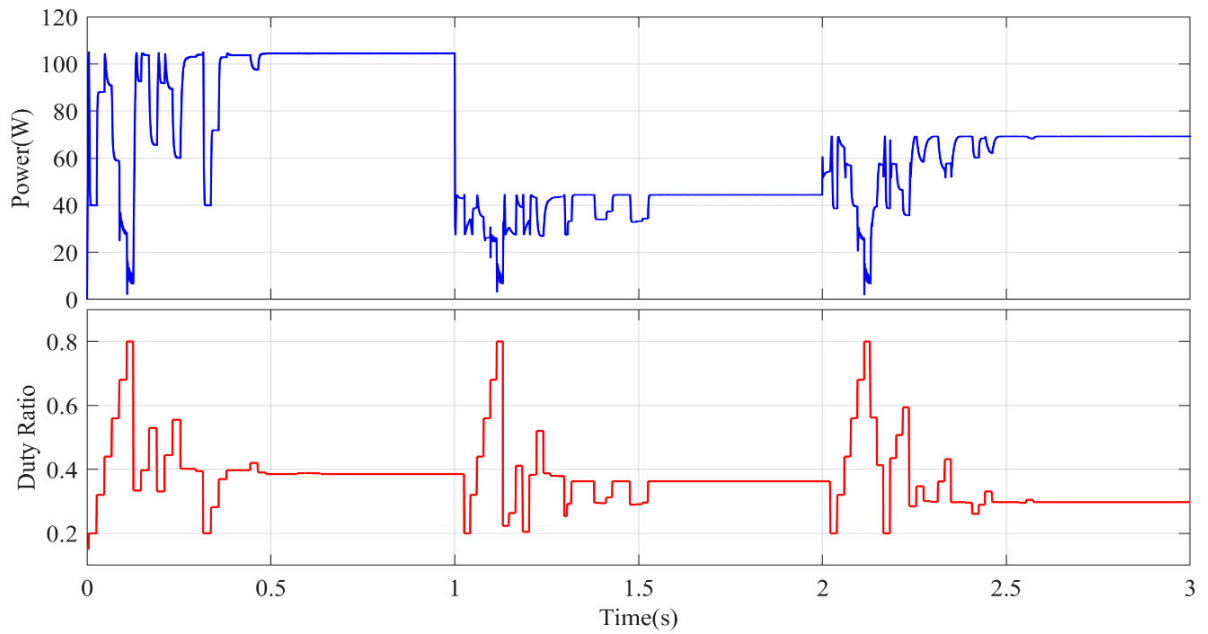

(d)

Figure 8. Dynamic performance under sudden irradiance changes: (a) Perturb \& Observe (P\&O) MPPT controller; (b) Particle Swarm Optimization (PSO) MPPT controller; (c) SSA MPPT controller; (d) SSA-GWO MPPT controller. 
Table 7. Results of different MPPT algorithms.

\begin{tabular}{ccccc}
\hline Cases & Algorithms & Tracking Time (s) & $\boldsymbol{P}_{\max }(\mathbf{W})$ & MPPT Efficiency \\
\hline & P\&O & 0.48 & 104.06 & $99.10 \%$ \\
Pattern 1 & PSO & 0.72 & 104.46 & $99.49 \%$ \\
$\mathrm{P}_{\text {real }}=105 \mathrm{~W}$ & SSA & 0.58 & 104.60 & $99.62 \%$ \\
& SSA-GWO & 0.46 & 104.88 & $99.89 \%$ \\
& P\&O & 0.16 & 34.64 & $77.69 \%$ \\
Pattern 2 & PSO & 0.64 & 44.47 & $99.71 \%$ \\
$\mathrm{P}_{\text {real }}=44.6 \mathrm{~W}$ & SSA & 0.52 & 44.49 & $99.75 \%$ \\
& SSA-GWO & 0.53 & 44.55 & $99.89 \%$ \\
Pattern 3 & P\&O & 0.35 & 68.22 & $98.30 \%$ \\
$\mathrm{P}_{\text {real }}=69.4 \mathrm{~W}$ & PSO & 0.68 & 69.19 & $99.70 \%$ \\
& SSA & 0.66 & 69.23 & $99.76 \%$ \\
& SSA-GWO & 0.47 & 69.32 & $99.88 \%$ \\
\hline
\end{tabular}

- Interval $1(0<\mathrm{t}<1 \mathrm{~s})$ : A standard irradiance pattern was implemented, i.e., $\mathrm{G} 1=\mathrm{G} 2=$ $\mathrm{G} 3=1000 \mathrm{~W} / \mathrm{m}^{2}$.

In this period, the standard irradiation was employed, GMPP is about $105 \mathrm{~W}$. It is clear that the $\mathrm{P} \& \mathrm{O}$ algorithm is able to track the MPP under uniform irradiance condition with only $0.48 \mathrm{~s}$, while the output power has relatively large oscillation around the maximum power, achieving $99.1 \%$ MPPT efficiency. The traditional PSO algorithm can locate the peak with zero oscillation, while it took $0.72 \mathrm{~s}$ to track the MPP with $99.49 \%$ MPPT efficiency. It can also be observed in Figure $8 \mathrm{~b}$ that the fluctuation in the process of tracking is high. Compared with the conventional P\&O and PSO algorithm, the SSA MPPT algorithm tracked the MPP with faster speed and higher efficiency, which are $0.58 \mathrm{~s}$ and $99.62 \%$, respectively. The improved SSA-GWO algorithm dominates the other three algorithms in terms of tracking speed (0.46 s) and MPPT efficiency (99.89\%). Meanwhile, power fluctuation was also reduced.

In addition, the waveform of duty ratio in Figure $8 \mathrm{~d}$ saw an expanded search region at around $0.3 \mathrm{~s}$, which indicates improved global search capability of the proposed algorithm.

- Interval $2(1<\mathrm{t}<2 \mathrm{sec})$ : At $\mathrm{t}=1 \mathrm{~s}$, a sudden irradiance change occurred, i.e., $\mathrm{G}_{2}=600 \mathrm{~W} / \mathrm{m}^{2}$, $\mathrm{G}_{3}=300 \mathrm{~W} / \mathrm{m}^{2}$.

When PSC occurred, the value and position of GMPP also changed. In Figure 8, it can be observed that the employed re-initialization method can effectively restart the MPPT algorithms between intervals. The $\mathrm{P} \& \mathrm{O}$ algorithm failed in the condition, causing great power losses. The MPPT speed for the four MPPT algorithms was $0.16,0.64,0.52$, and $0.53 \mathrm{~s}$.

According to the results, $P_{\max }$ was $34.64,44.47,44.49$, and $44.55 \mathrm{~W}$, while the MPPT efficiency was $77.69 \%, 99.71 \%, 99.75 \%$, and $99.89 \%$ using the four MPPT methods, respectively, as listed in Table 7 . It is obvious that the proposed SSA-GWO has the best overall performance considering tracking speed and MPPT efficiency.

- Interval $3(2<\mathrm{t}<3 \mathrm{~s})$ : At $\mathrm{t}=2 \mathrm{~s}$, a sudden irradiance change occurred, i.e., $\mathrm{G} 2=800 \mathrm{~W} / \mathrm{m}^{2}$, $\mathrm{G} 3=600 \mathrm{~W} / \mathrm{m}^{2}$.

Though it takes $0.35 \mathrm{~s}$ for the P\&O MPPT algorithm to track the MPP, the P\&O method scanned the $\mathrm{P}-\mathrm{V}$ curve from right to left. Hence, $\mathrm{P} \& \mathrm{O}$ algorithm was actually trapped in the third peak of the $\mathrm{P}-\mathrm{V}$ curve, which happened to be the GMPP. Besides this, the output power still fluctuated around the MPP. It took $0.68,0.66$, and $0.47 \mathrm{~s}$ for the PSO, SSA and proposed SSA-GWO algorithms to acquire the GMPP. $P_{\max }$ was $68.22,69.19,69.23$, and $69.32 \mathrm{~W}$, while the MPPT efficiency was $98.30 \%, 99.70 \%, 99.76 \%$, and $99.88 \%$ using the four MPPT methods, respectively. The proposed SSA-GWO algorithm had the best performance in terms of tracking speed and MPPT efficiency. Furthermore, the power fluctuation with the proposed SSA-GWO MPPT algorithm was lower than the counterpart MPPT algorithms, as is shown in Figure 8. Therefore, the PV system has a better dynamic with higher output power. 


\section{Conclusions}

In this paper, a novel SSA-GWO MPPT algorithm was proposed for PV systems to track GMPP under diverse PSCs. In the proposed SSA-GWO algorithm, the GWO algorithm was integrated into the SSA algorithm to enhance the global search capability and high tracking efficiency, and half the salps were selected into a leader group and the rest were followers. Meanwhile, it still maintains the adaptive mechanism of the SSA algorithm, which is able to avoid stagnating in local best solutions. Numerical simulation analysis was done on benchmark functions and the results verified that the proposed SSA-GWO algorithm outperforms the PSO and basic SSA algorithms in most cases. Furthermore, the MPPT results tested on the PV system simulation platform validated the effectiveness and superiority of the proposed SSA-GWO MPPT algorithm. Compared with other MPPT algorithms, the proposed MPPT method has the following advantages: (1) fast and accurate GMPP tracking performance for real-time MPPT control of PV system, (2) capability of dealing with both static partial shading condition and dynamic irradiance change, and (3) reduced power fluctuation.

Author Contributions: Y.W. proposed the main idea, performed the simulation experiments, did the calculation, and wrote the paper. M.M. designed the validation methods and contributed to the discussion of this research. L.Z., M.M., Q.Z., X.X. and C.Z. double-checked and revised the whole manuscript.

Funding: This work has been supported by the China Postdoctoral Science Foundation (Grant No. 2018M643410), the Chongqing Special Postdoctoral Science Foundation (Grant No. XmT2018033), the Graduate Research and Innovation Foundation of Chongqing, China (Grant No. CYS18007), the National Natural Science Foundation of China (Grant No. 51707026) and the National "111" Project of China under Grant B808036.

Conflicts of Interest: The authors declare no conflict of interest.

\section{References}

1. Subudhi, B.; Pradhan, R. A comparative study on maximum power point tracking techniques for photovoltaic power systems. IEEE Trans. Sustain. Energy 2013, 4, 89-98. [CrossRef]

2. Femia, N.; Petrone, G.; Spagnuolo, G.; Vitelli, M. Optimization of perturb and observe maximum power point tracking method. IEEE Trans. Power Electron. 2005, 20, 963-973. [CrossRef]

3. Tey, K.S.; Mekhilef, S. Modified incremental conductance algorithm for photovoltaic system under partial shading conditions and load variation. IEEE Trans. Ind. Electron. 2014, 61, 5384-5392.

4. Amir, A.; Amir, A.; Selvaraj, J.; Rahim, N.A.; Abusorrah, A.M. Conventional and modified MPPT techniques with direct control and dual scaled adaptive step-size. Sol. Energy 2017, 157, 1017-1031. [CrossRef]

5. Olalla, C.; Clement, D.; Rodriguez, M.; Maksimovic, D. Architectures and control of submodule integrated DC-DC converters for photovoltaic applications. IEEE Trans. Power Electron. 2013, 28, 2980-2997. [CrossRef]

6. Necaibia, S.; Kelaiaia, M.S.; Labar, H.; Necaibia, A.; Castronuovo, E.D. Enhanced auto-scaling incremental conductance MPPT method, implemented on low-cost microcontroller and SEPIC converter. Sol. Energy 2019, 180, 152-168. [CrossRef]

7. Ghasemi, M.A.; Foroushani, H.M.; Parniani, M. Partial shading detection and smooth maximum power point tracking of PV arrays under PSC. IEEE Trans. Power Electron. 2016, 31, 6281-6292. [CrossRef]

8. Hammami, M.; Ricco, M.; Ruderman, A.; Grandi, G. Three-Phase Three-Level Flying Capacitor PV Generation System with an Embedded Ripple Correlation Control MPPT Algorithm. Electronics 2019, 8, 118. [CrossRef]

9. Afzal Awan, M.; Mahmood, T. A Novel Ten Check Maximum Power Point Tracking Algorithm for a Standalone Solar Photovoltaic System. Electronics 2018, 7, 327. [CrossRef]

10. Baimel, D.; Tapuchi, S.; Levron, Y.; Belikov, J. Improved Fractional Open Circuit Voltage MPPT Methods for PV Systems. Electronics 2019, 8, 321. [CrossRef]

11. Yilmaz, U.; Kircay, A.; Borekci, S. PV system fuzzy logic MPPT method and PI control as a charge controller. Renew. Sustain. Energy Rev. 2018, 81, 994-1001. [CrossRef]

12. Li, X.; Wen, H.; Hu, Y.; Jiang, L. A novel beta parameter based fuzzy-logic controller for photovoltaic MPPT application. Renew. Energy 2019, 130, 416-427. [CrossRef]

13. Wang, Y.; Yang, Y.; Fang, G.; Zhang, B.; Wen, H.; Tang, H.; Fu, L.; Chen, X. An Advanced Maximum Power Point Tracking Method for Photovoltaic Systems by Using Variable Universe Fuzzy Logic Control Considering Temperature Variability. Electronics 2018, 7, 355. [CrossRef] 
14. Rizzo, S.A.; Scelba, G. ANN based MPPT method for rapidly variable shading conditions. Appl. Energy 2015, 145, 124-132. [CrossRef]

15. Chine, W.; Mellit, A.; Lughi, V.; Malek, A.; Sulligoi, G.; Pavan, A.M. A novel fault diagnosis technique for photovoltaic systems based on artificial neural networks. Renew. Energy 2016, 90, 501-512. [CrossRef]

16. Robles Algarín, C.; Sevilla Hernández, D.; Restrepo Leal, D. A low-cost maximum power point tracking system based on neural network inverse model controller. Electronics 2018, 7, 4. [CrossRef]

17. Jiang, L.L.; Srivatsan, R.; Maskell, D.L. Computational intelligence techniques for maximum power point tracking in PV systems: A review. Renew. Sustain. Energy Rev. 2018, 85, 14-45. [CrossRef]

18. Liu, Y.-H.; Huang, S.-C.; Huang, J.-W.; Liang, W.-C. A particle swarm optimization-based maximum power point tracking algorithm for PV systems operating under partially shaded conditions. IEEE Tran. Energy Convers. 2012, 27, 1027-1035. [CrossRef]

19. Mao, M.; Duan, Q.; Yang, Z.; Duan, P. Modeling and global MPPT for PV system under partial shading conditions using modified artificial fish swarm algorithm. In Proceedings of the 2016 IEEE International Symposium on Systems Engineering (ISSE), Edinburgh, UK, 3-5 October 2016; pp. 1-7.

20. Soufyane Benyoucef, A.; Chouder, A.; Kara, K.; Silvestre, S. Artificial bee colony based algorithm for maximum power point tracking (MPPT) for PV systems operating under partial shaded conditions. Appl. Soft Comput. 2015, 32, 38-48. [CrossRef]

21. Mao, M.; Zhang, L.; Duan, P.; Duan, Q.; Yang, M. Grid-connected modular PV-Converter system with shuffled frog leaping algorithm based DMPPT controller. Energy 2018, 143, 181-190. [CrossRef]

22. Mohanty, S.; Subudhi, B.; Ray, P.K. A new MPPT design using grey wolf optimization technique for photovoltaic system under partial shading conditions. IEEE Trans. Sustain. Energy 2016, 7, 181-188. [CrossRef]

23. Eltamaly, A.M.; Farh, H.M. Dynamic global maximum power point tracking of the PV systems under variant partial shading using hybrid GWO-FLC. Sol. Energy 2019, 177, 306-316. [CrossRef]

24. Sundareswaran, K.; Peddapati, S.; Palani, S. MPPT of PV systems under partial shaded conditions through a colony of flashing fireflies. IEEE Trans. Energy Convers. 2014, 29, 463-472.

25. Koad, R.B.; Zobaa, A.F.; El-Shahat, A. A novel MPPT algorithm based on particle swarm optimization for photovoltaic systems. IEEE Trans. Sustain. Energy 2017, 8, 468-476. [CrossRef]

26. Li, H.; Yang, D.; Su, W.; Lü, J.; Yu, X. An overall distribution particle swarm optimization MPPT algorithm for photovoltaic system under partial shading. IEEE Trans. Ind. Electron. 2019, 66, 265-275. [CrossRef]

27. Sundareswaran, K.; Palani, S. Application of a combined particle swarm optimization and perturb and observe method for MPPT in PV systems under partial shading conditions. Renew. Energy 2015, 75, 308-317. [CrossRef]

28. Pilakkat, D.; Kanthalakshmi, S. An improved P\&O algorithm integrated with artificial bee colony for photovoltaic systems under partial shading conditions. Sol. Energy 2019, 178, 37-47.

29. Mirjalili, S.; Gandomi, A.H.; Mirjalili, S.Z.; Saremi, S.; Faris, H.; Mirjalili, S.M. Salp Swarm Algorithm: A bio-inspired optimizer for engineering design problems. Adv. Eng. Softw. 2017, 114, 163-191. [CrossRef]

30. Mirjalili, S.; Mirjalili, S.M.; Lewis, A. Grey wolf optimizer. Adv. Eng. Softw. 2014, 69, 46-61. [CrossRef]

31. Tsai, H.L.; Tu, C.S.; Su, Y.J. Development of generalized photovoltaic model using MATLAB/Simulink. In Proceedings of the World Congress on Engineering and Computer Science, San Francisco, CA, USA, 22-24 October 2008; pp. 846-851.

(C) 2019 by the authors. Licensee MDPI, Basel, Switzerland. This article is an open access article distributed under the terms and conditions of the Creative Commons Attribution (CC BY) license (http://creativecommons.org/licenses/by/4.0/). 